\title{
Non-Dilatant Brittle Deformation and Strength Reduction of Olivine Gabbro due to Hydration
}

\author{
Yuya Akamatsu*D, Kumpei Nagase and Ikuo Katayama \\ Department of Earth and Planetary Systems Science, Hiroshima University, Hiroshima 739-8526, Japan; \\ kumpei-nagase@hiroshima-u.ac.jp (K.N.); katayama@hiroshima-u.ac.jp (I.K.) \\ * Correspondence: y-akamatsu@hiroshima-u.ac.jp
}

Citation: Akamatsu, Y.; Nagase, K.; Katayama, I. Non-Dilatant Brittle Deformation and Strength Reduction of Olivine Gabbro due to Hydration. Minerals 2021, 11, 694. https:// doi.org/10.3390/min11070694

Academic Editors: Jacques Précigout and Cécile Prigent

Received: 13 April 2021

Accepted: 25 June 2021

Published: 28 June 2021

Publisher's Note: MDPI stays neutral with regard to jurisdictional claims in published maps and institutional affiliations.

Copyright: (c) 2021 by the authors. Licensee MDPI, Basel, Switzerland. This article is an open access article distributed under the terms and conditions of the Creative Commons Attribution (CC BY) license (https:// creativecommons.org/licenses/by/ $4.0 /)$.

\begin{abstract}
To investigate the influence of hydration on brittle deformation of oceanic crustal rocks, we conducted triaxial deformation experiments on gabbroic rocks with various degrees of hydration at a confining pressure of $20 \mathrm{MPa}$ and room temperature, measuring elastic wave velocity. Hydrated olivine gabbros reached a maximum differential stress of 225-350 MPa, which was considerably less than those recorded for gabbros ( 450 MPa), but comparable to those for serpentinized ultramafic rocks (250-300 MPa). Elastic wave velocities of hydrated olivine gabbros did not show a marked decrease even prior to failure. This indicated that the deformation of hydrated olivine gabbro is not associated with the opening of the stress-induced cracks that are responsible for dilatancy. Microstructural observations of the samples recovered after deformation showed crack damage to be highly localized to fault zones with no trace of stress-induced crack opening, consistent with the absence of dilatancy. These data suggest that strain localization of hydrated olivine gabbro can be caused by the development of shear cracks in hydrous minerals such as serpentine and chlorite, even when they are present in only small amounts. Our results suggest that the brittle behavior of the oceanic crust may considerably change due to limited hydration.
\end{abstract}

Keywords: gabbro; olivine gabbro; hydration; brittle strength; elastic wave velocity; serpentine; chlorite

\section{Introduction}

Oceanic plates experience hydration due to water-rock interactions associated with various tectonic and magmatic processes affecting the seafloor. Hydrous minerals such as serpentine, which result from the hydration of mafic and ultramafic rocks, have unique physical and mechanical properties [1]; therefore, hydration of the oceanic plates is a key influence on several aspects of geodynamic processes in various tectonic settings such as slow-spreading ridges (e.g., [2]) and subduction zones (e.g., [3]).

Laboratory deformation experiments have shown that, in the brittle regime, serpentinite deforms without the stress-induced opening of cracks that is typically observed in deforming polycrystalline rocks, such as granite, because the failure occurs purely by sliding (i.e., shear cracking) preferentially along the mechanically weak (001) cleavage plane of serpentine [2]. Since shear cracks do not involve any porosity change, the elastic wave velocity of serpentinite is insensitive to brittle deformation [4], whereas that of granite systematically decreases during deformation, owing to the opening of cracks [5]. Escartín et al. [6] conducted triaxial deformation experiments to quantify the effect of serpentinization on the mechanical properties of peridotite. They found that the presence of only $\sim 10 \%$ serpentine governs the mode of brittle deformation of peridotite, resulting in an absence of significant volume change during deformation and a decrease in fracture strength to that of serpentinite. Although the influence of hydration on the physical and mechanical properties of mantle rocks has been well investigated by previous deformation experiments, the effects of hydration on gabbroic crustal rocks have not yet been constrained. Gabbroic rocks containing serpentinized olivine grains are commonly sampled 
from tectonic settings such as oceanic core complexes [7-10], transform faults [11,12], and ophiolites $[13,14]$. In addition, recent geophysical surveys have observed low-velocity zones in the incoming plate at outer-rise regions, indicating that hydration occurs even to the depths of the mantle, owing to bending-related faulting [15-23]. Even a small amount of mechanically weak hydrous minerals can drastically change the rheological behavior of bulk rock [6,24]; therefore, understanding the effect of hydration on gabbroic crustal rocks is essential for interpreting the mechanical behavior of the oceanic plate, and associated seismological signatures, where hydration occurs.

In this study, we performed triaxial deformation experiments on gabbros and olivinebearing gabbros containing hydrous minerals such as serpentine and chlorite at a confining pressure of $20 \mathrm{MPa}$ and room temperature, to investigate the influence of hydration on brittle deformation in crustal rocks. We compare the results to those of additional experiments conducted on serpentinite and serpentinized peridotite samples. Elastic wave velocities were measured during the deformation experiments to monitor the development of stressinduced cracks $[4,25-30]$. We conclude by discussing the implications of our mechanical and velocity data for understanding the effects of hydration on the brittle behavior of the oceanic lithosphere.

\section{Methods}

\subsection{Sample Descriptions}

Deformation experiments were conducted on nine samples of varying lithology, including olivine gabbros, gabbros, serpentinized peridotite, and lizardite serpentinite. Representative micrographs of the experimental samples are shown in Figure 1. Gabbro samples (OM-10 and OM-17) were collected from the Samail ophiolite in Oman and are composed of plagioclase, clinopyroxene, and minor amounts of hornblende and epidote (Figure 1a,b). Olivine gabbro samples OG1, CM1A-113z, and OM-4 were also collected from the Samail ophiolite, and sample HK-25 was collected from the Horoman Complex in Japan. CM1A-113z is an olivine gabbro core sample recovered by the Oman Drilling Project, which sampled drill cores throughout the fossilized crust-mantle transition zone in the Samail ophiolite [13]. These olivine gabbros consist mainly of plagioclase, clinopyroxene, and $15-36 \%$ of primary olivine. The olivine grains were variably hydrated, with serpentine and chlorite contents of between $6 \%$ and $27 \%$ (Table 1). The serpentine in samples OM-4, CM1A-113z, and HK-25 forms a mesh texture (Figure 1) that is indicative of low temperature serpentinization and is commonly observed in serpentinized peridotite. No mesh texture is observed in samples OG-1.1 and OG-1.2 (Figure 1c); however, some olivine grains show replacement by serpentine and chlorite along grain boundaries, while others have undergone complete hydration and exhibit a pseudomorph of serpentine and chlorite. These olivine gabbro samples contain cracks cutting the plagioclase, which are micrometer- or millimeter-sized and commonly filled with chlorite (Figure 1). These cracks are possibly formed by volume expansion associated with olivine hydration [31], or tensile stress due to tectonic activity or thermal contraction near mid-ocean ridges [32]. Serpentinized peridotite (ST-12) and lizardite serpentinite (MK7-05) samples were collected from the Samail ophiolite in Oman and the accretionary prism in the Mineoka Belt in Japan, respectively. These ultramafic rock samples are composed of primary olivine, orthopyroxene, lizardite, and chrysotile. Based on calculation of the degree of serpentinization by Escartín et al. [6], which uses the relationship between grain density and serpentinization, the serpentinization degree is estimated as 51\% in ST- 12 and 90\% in MK7-05. The representative micrographs show serpentine mesh textures in both of these samples (Figure 1g,h). The experimental samples were cored into cylinders of $20 \mathrm{~mm}$ in diameter and $40 \mathrm{~mm}$ in length, and the flat end surfaces ground parallel to within $0.01 \mathrm{~mm}$. Sample densities and porosities were calculated from dry and wet masses at ambient conditions (Table 1). All specimens were dried in an oven at $70^{\circ} \mathrm{C}$ for at least $24 \mathrm{~h}$ prior to deformation experiments. 

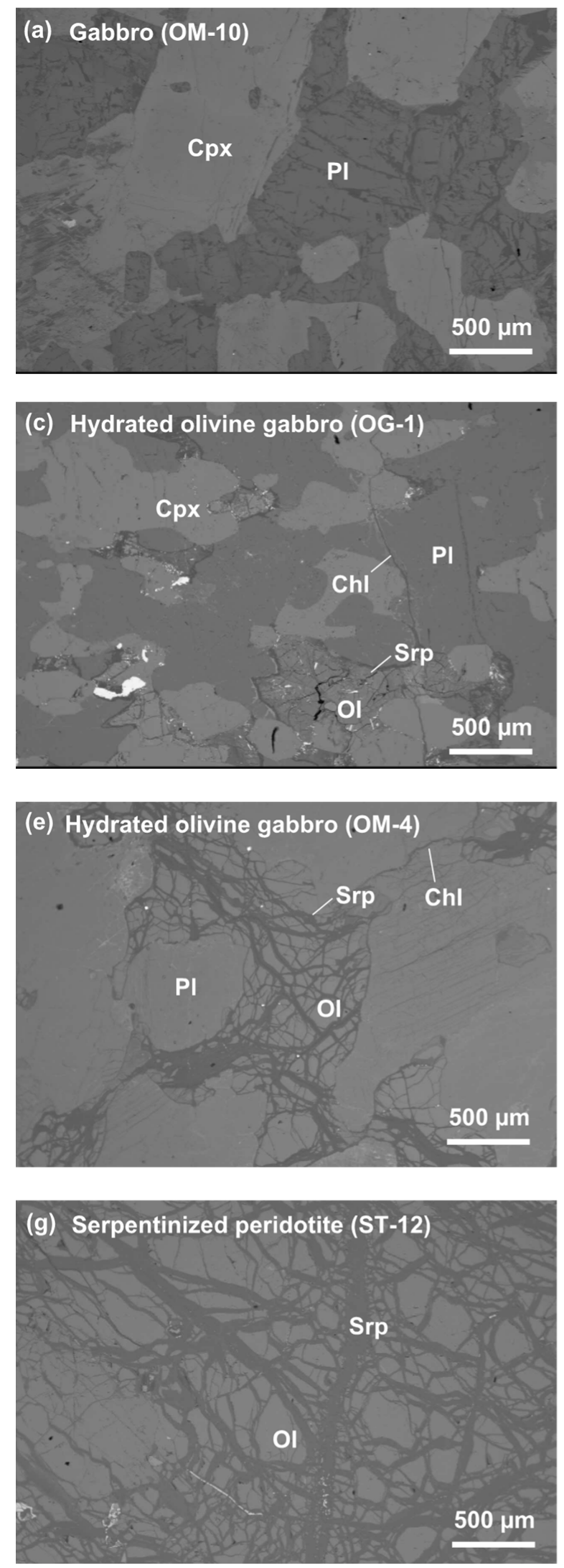

(b) Gabbro (OM-17)

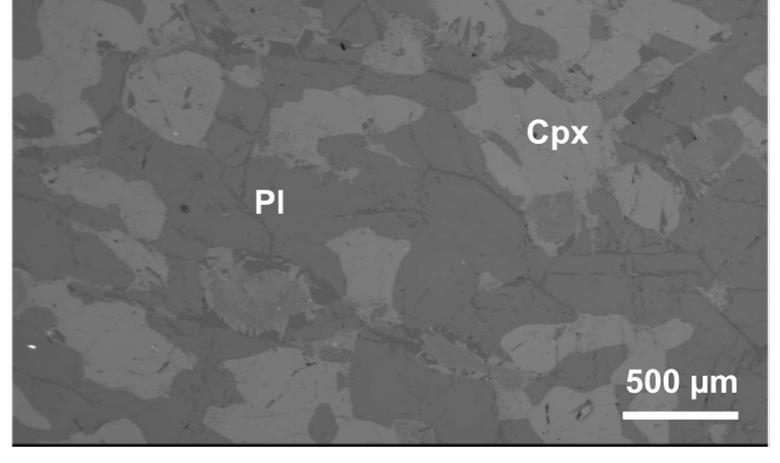

(d) Hydrated olivine gabbro (HK-25)
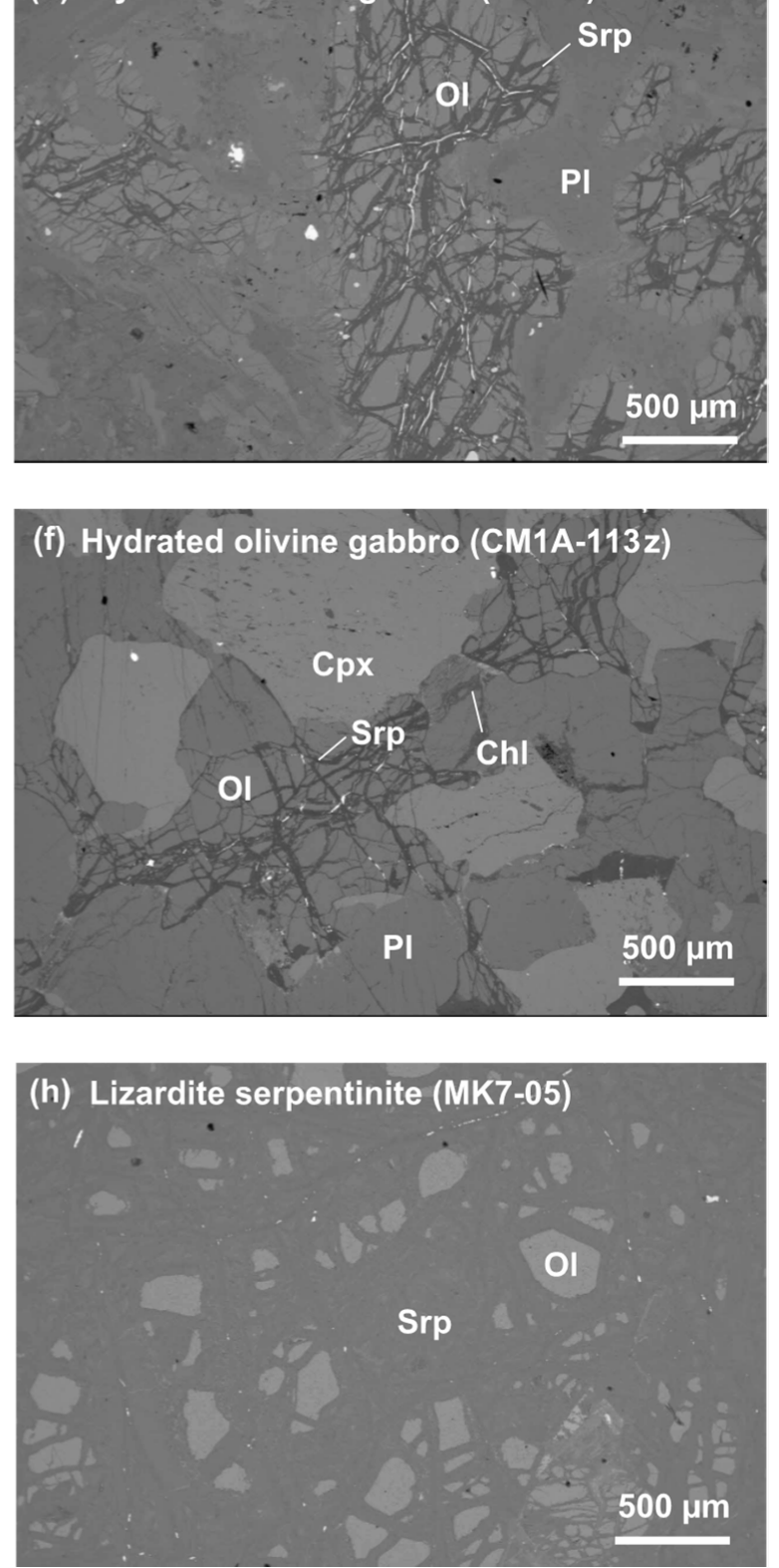

Figure 1. SEM images of each experimental sample: gabbro $(\mathbf{a}, \mathbf{b})$, hydrated olivine gabbro $(\mathbf{c}-\mathbf{f})$, serpentinized peridotite $(\mathbf{g})$, and lizardite serpentinite (h). Abbreviations for minerals: Cpx, Clinopyroxene; Pl, Plagioclase; Ol, Olivine; Srp, Serpentine; Chl, Chlorite. 
Table 1. Sample descriptions.

\begin{tabular}{|c|c|c|c|c|c|c|c|c|}
\hline \multirow{2}{*}{ Sample } & \multirow{2}{*}{ Rock Type } & \multirow{2}{*}{ Locality } & \multicolumn{2}{|c|}{ Mineral Content (\%) } & \multirow{2}{*}{$\begin{array}{l}\text { Density } \\
\left(\mathrm{g} / \mathrm{cm}^{3}\right)\end{array}$} & \multirow{2}{*}{$\begin{array}{c}\text { Initial } \\
\text { Porosity (\%) }\end{array}$} & \multirow{2}{*}{$\begin{array}{c}\text { Initial } V_{S} \\
\text { Anisotropy } \\
(\%)^{b}\end{array}$} & \multirow{2}{*}{$\begin{array}{c}\text { Maximum } \\
\text { Differential Stress } \\
(\mathrm{MPa})\end{array}$} \\
\hline & & & Ol & Srp + Chl & & & & \\
\hline OG-1.1 & $\begin{array}{l}\text { Olivine } \\
\text { gabbro }\end{array}$ & Oman & $7(15)$ & 8 & 3.01 & 0.11 & 1.96 & 305 \\
\hline OG-1.2 & $\begin{array}{l}\text { Olivine } \\
\text { gabbro }\end{array}$ & Oman & $7(15)$ & 8 & 3.01 & 0.11 & 1.36 & 348 \\
\hline CM1A-113z & $\begin{array}{l}\text { Olivine } \\
\text { gabbro }\end{array}$ & Oman & $9(15)$ & 6 & 2.98 & 0.05 & 1.30 & 225 \\
\hline HK-25 & $\begin{array}{l}\text { Olivine } \\
\text { gabbro }\end{array}$ & Horoman & $9(36)$ & 27 & 3.01 & 0.46 & 4.15 & 302 \\
\hline OM-4 & $\begin{array}{l}\text { Olivine } \\
\text { gabbro }\end{array}$ & Oman & $9(22)$ & 13 & 2.86 & 0.08 & 2.06 & 344 \\
\hline OM-17 & Gabbro & Oman & 0 & 0 & 2.95 & 0.14 & 0.65 & 457 \\
\hline OM-10 & Gabbro & Oman & 0 & 0 & 2.97 & 0.24 & 0.53 & 440 \\
\hline ST-12 & Peridotite & Oman & $40(100)^{a}$ & 60 & 2.93 & 0.49 & 10.2 & 257 \\
\hline MK7-05 & Serpentinite & Mineoka & $12(100)^{a}$ & 88 & 2.63 & 1.56 & 1.72 & 300 \\
\hline
\end{tabular}

Abbreviations correspond to those in Figure 1. The numbers inside parentheses show the estimated primary content (i.e., $\mathrm{Ol}+\mathrm{Srp}+\mathrm{Chl}$ ).

${ }^{a}$ Primary orthopyroxene content is included. ${ }^{\mathrm{b}}$ These are the absolute values of S-wave anisotropy $A_{\mathrm{S}}$ before applying differential stress.

\subsection{Experimental Procedure}

Triaxial deformation experiments were performed using the intra-vessel deformation and fluid flow apparatus at Hiroshima University (Hiroshima, Japan); please see [29] for more detail about the apparatus. All experiments were conducted under dry conditions at a constant displacement rate of $0.002-0.003 \mathrm{~mm} / \mathrm{min}$ (corresponding to an equivalent strain rate of $\sim 10^{-6} \mathrm{~s}^{-1}$ ), at room temperature, and with a confining pressure of $20 \mathrm{MPa}$. The confining pressure was set to a constant value using a servo-controlled system to compensate for the piston movement during deformation. Axial displacement was measured by the external displacement transducer, while differential stress was determined from the difference between the axial and confining pressure, with an accuracy of $0.5 \mathrm{MPa}$. A machine stiffness correction was applied to the axial displacement data to account for mechanical distortion during deformation. The mechanical parameters were recorded by a data logger at a sampling rate of $1 \mathrm{~Hz}$. As our experimental apparatus was not equipped with a high-resolution feedback system, the data logging was stopped immediately after the macroscopic failure; therefore, we focused on the evolution of elastic wave velocities approaching the maximum differential stress, but not during the post-failure processes. The sample was jacketed in a polyolefin tube and silicone to separate it from the oil confining medium. Elastic wave velocities were measured with lead zirconate titanate piezoelectric transducers of resonant frequency $2 \mathrm{MHz}$, using a pulse transmission method. Both P-wave and S-wave velocity data were acquired along the direction normal to the loading axis (Figure 2). S-waves were polarized in the planes perpendicular (SH-wave) and parallel (SV-wave) to the loading axis $\left(\sigma_{1}\right)$. An input pulse with an amplitude of $5 \mathrm{~V}$ and frequency of $2 \mathrm{MHz}$ was sent to each transducer by a function generator, and the output signal was received by the remaining transducers and digitalized by an oscilloscope. The velocity was then determined by dividing the path length by the travel time. The error in ultrasonic velocities was estimated as $<1 \%$, which reflects the picking accuracy of wave arrival times and possible changes in propagation path length owing to sample dilation during deformation. The S-wave anisotropy $A_{\mathrm{S}}$ is calculated from $\mathrm{SH}$-wave velocity $V_{\mathrm{SH}}$ and $\mathrm{SV}$-wave velocity $V_{\mathrm{SV}}$ as:

$$
A_{\mathrm{S}}=\frac{V_{\mathrm{SH}}-V_{\mathrm{SV}}}{\bar{V}_{\mathrm{S}}} \times 100,
$$

where $\bar{V}_{\mathrm{S}}=\left(V_{\mathrm{SH}}+V_{\mathrm{SV}}\right) / 2$ [33]. The absolute values of $A_{\mathrm{S}}$ prior to the deformation of each sample are listed in Table 1. 
(a)

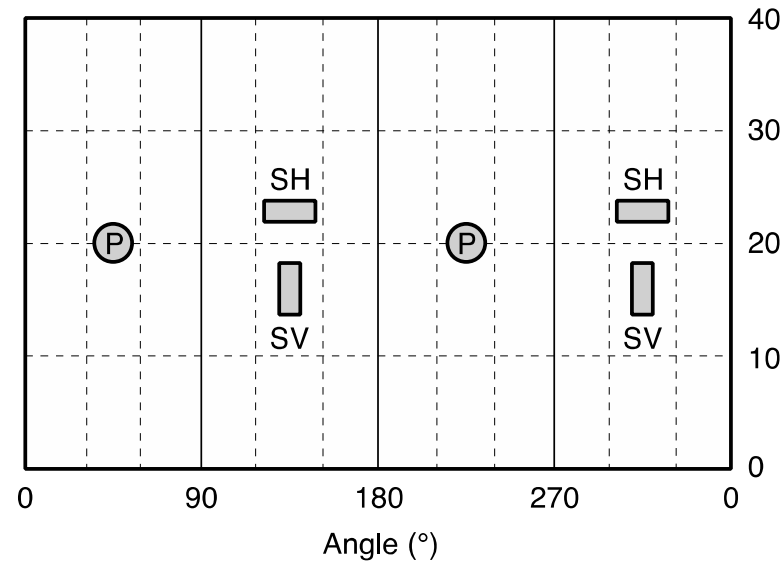

(b)

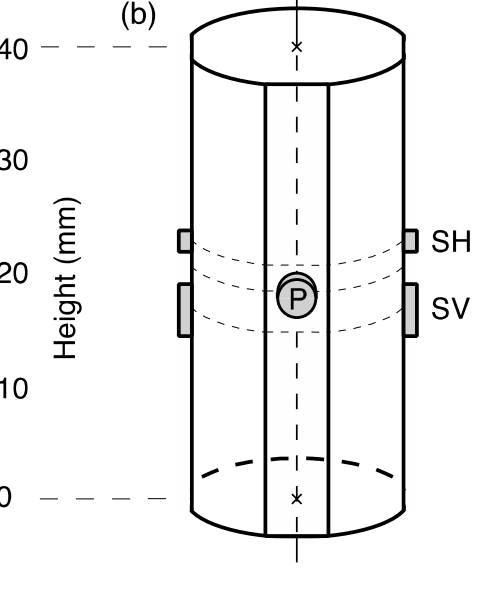

Figure 2. (a) Map of sensors around the sample. One P-wave and two S-waves along a direction perpendicular to the loading axis were generated by lead zirconate titanate piezoelectric transducers. $\mathrm{S}$-waves were polarized in the planes horizontal (SH-wave) and perpendicular (SV-wave) to the axis. (b) Schematic view of a prepared sample.

\section{Results}

\subsection{Mechanical Data}

Figure 3 shows the mechanical data obtained from the deformation experiments, with differential stress plotted as a function of axial displacement (strain). The results of the experiments are summarized in Table 1. Maximum differential stresses of $\sim 450 \mathrm{MPa}$ are recorded for the gabbro samples, which are comparable to those of granite deformed under similar conditions [29]. Hydrated olivine gabbro samples with hydrous mineral contents of $6-27 \%$ yielded maximum differential stresses ranging from 225 to $348 \mathrm{MPa}$. These values are $20-50 \%$ less than that those of gabbros but are similar to those of serpentinized peridotite and lizardite serpentinite (257-300 MPa).

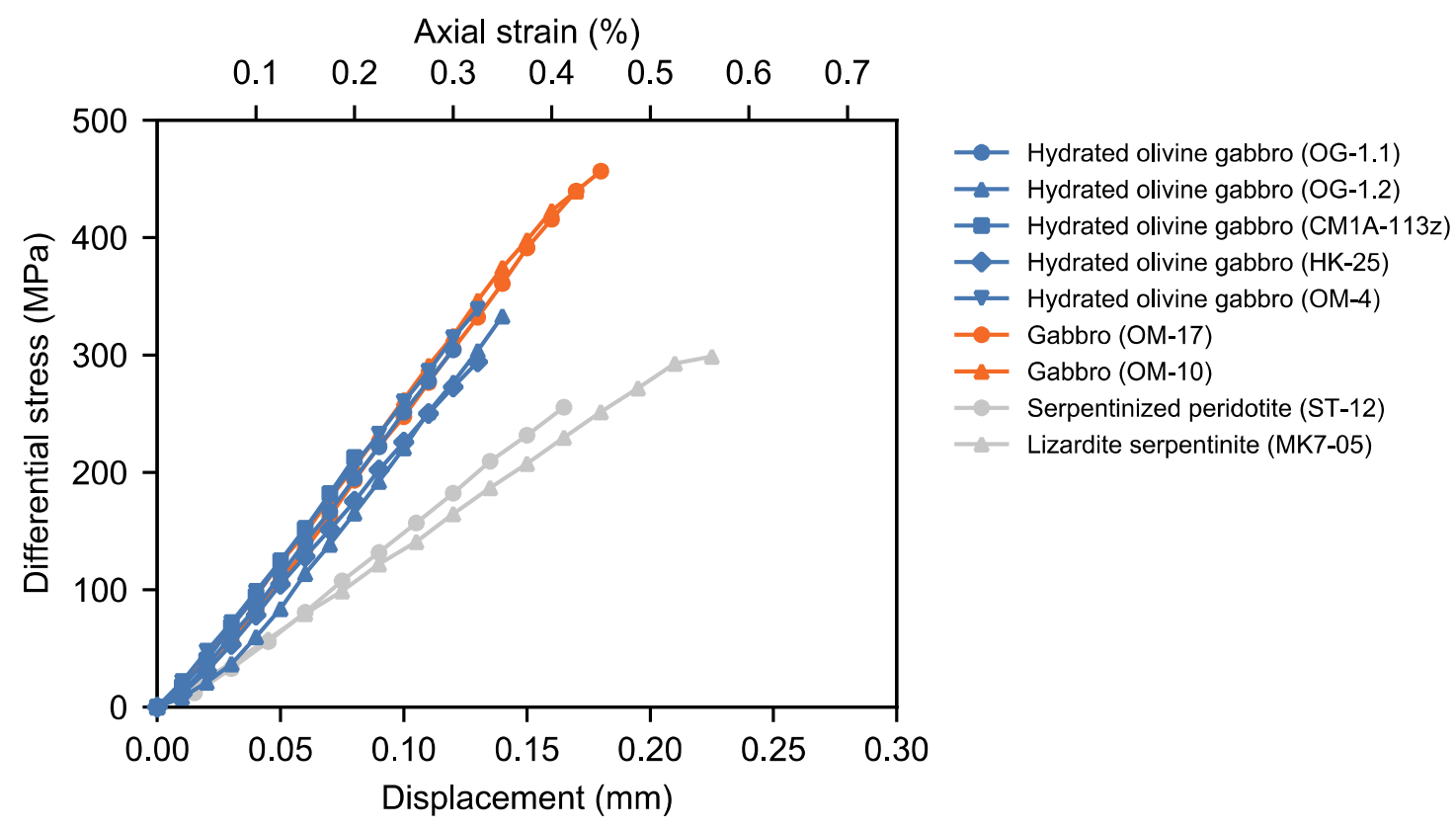

Figure 3. Mechanical data for each triaxial deformation experiment. Differential stress is plotted as a function of axial displacement. Axial strain, as inferred from displacement, is also shown on the upper axis. 
Figure 4 shows the relationship between the maximum differential stress and the hydrous mineral content for each sample. The brittle strength of gabbroic rocks decreases nonlinearly with hydrous mineral content. Beyond hydrous mineral content $6 \%$, the maximum differential stress of hydrated olivine gabbro decreases from values of gabbro to those close to lizardite serpentinite and serpentinized peridotite. Such strength reduction has also been reported to occur as a result of hydration in peridotite. Experiments by Escartín et al. [2] found the strength of peridotite to be a strongly nonlinear function of serpentinization. They observed that the strength of peridotite with $\sim 10 \%$ serpentine was comparable to that of pure serpentinite and were able to explain this strength reduction as a result of the accommodation of deformation by interconnected serpentine grains, which are substantially weaker than olivine. We observe a similar relationship to that of peridotite in our deformation experiments, which suggests that the strength reduction in gabbroic rocks occurs due to the presence of hydrous minerals such as serpentine and chlorite.

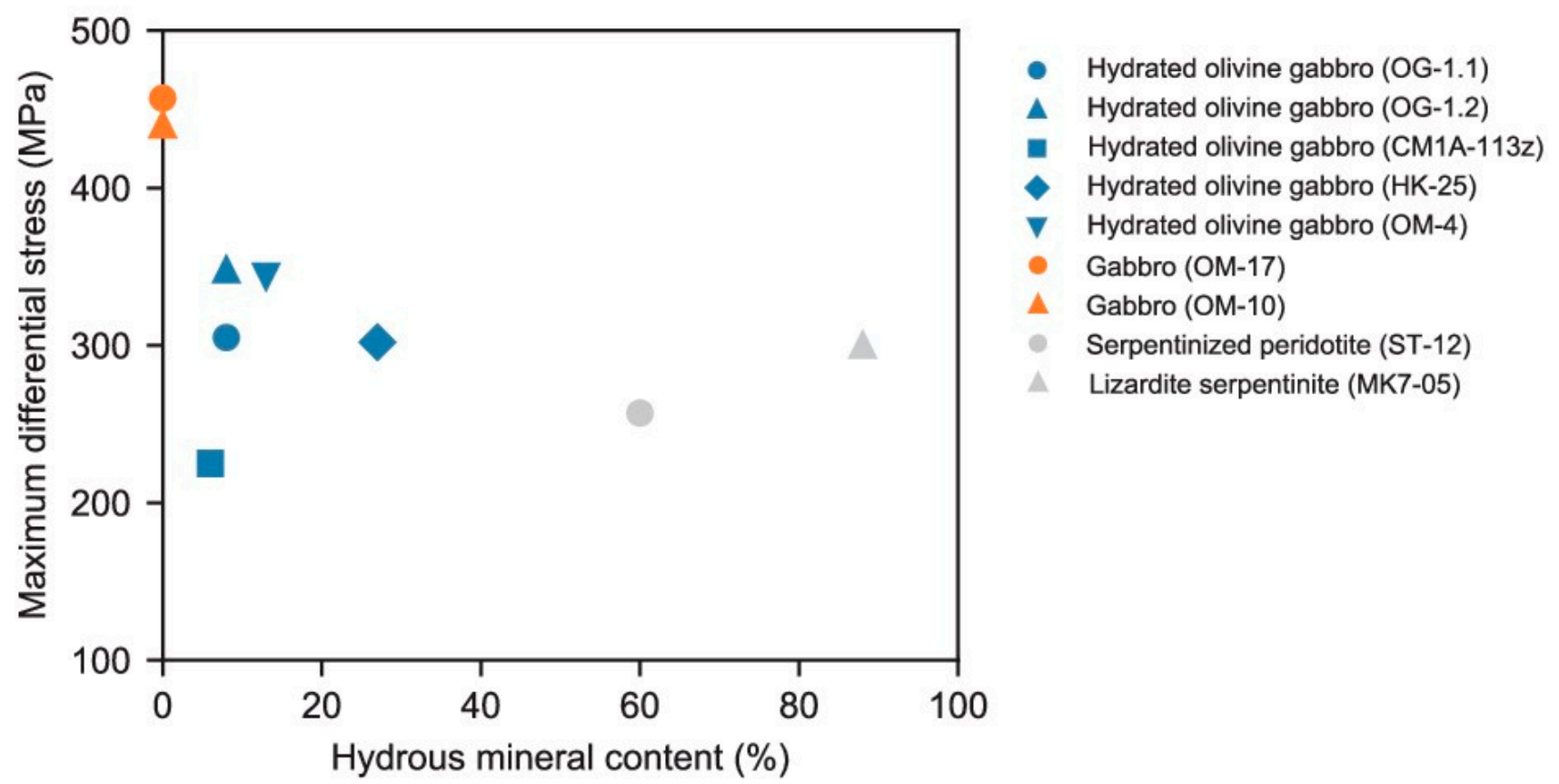

Figure 4. Relationship between the maximum differential stress and the hydrous mineral content of each sample.

\subsection{Elastic Wave Velocity}

During deformation of gabbro samples, the measured elastic wave velocities remained nearly constant as the differential stress increased to approximately two-thirds of its maximum value, but then began to decrease with increasing differential stress (Figure 5). Prior to failure, the P-wave velocities $V_{\mathrm{P}}$ had decreased by up to $20 \%$ of their initial values. For S-waves, the decrease prior to failure was much larger in the horizontally polarized S-wave velocity $V_{\mathrm{SH}}$ than the vertically polarized S-wave velocity $V_{\mathrm{SV}}$. The S-wave anisotropy in gabbro samples increased systematically as the samples approached the maximum stress (Figure 6). Similar changes in elastic wave velocities and anisotropy with deformation have been reported for a number of crystalline rocks and are associated with the development of tensile cracks along the axis of maximum compressive stress $\sigma_{1}[25-28,30,34]$. 


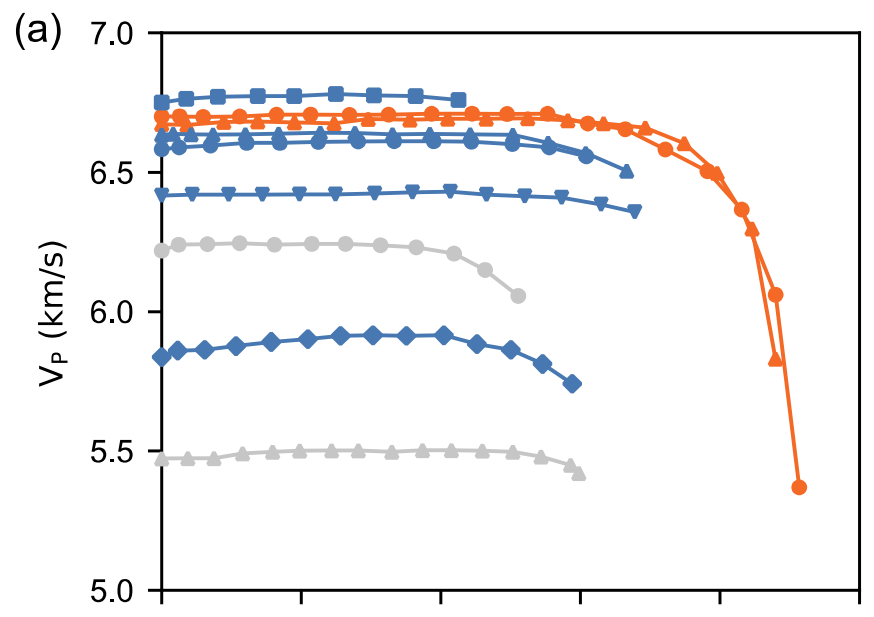

- Hydrated olivine gabbro (OG-1.1)

- Hydrated olivine gabbro (OG-1.2)

- Hydrated olivine gabbro (CM1A-113z)

$\neg$ Hydrated olivine gabbro (HK-25)

$\rightarrow$ Hydrated olivine gabbro (OM-4)

-- Gabbro (OM-17)

- Gabbro (OM-10)

- Serpentinized peridotite (ST-12)

- Lizardite serpentinite (MK7-05)
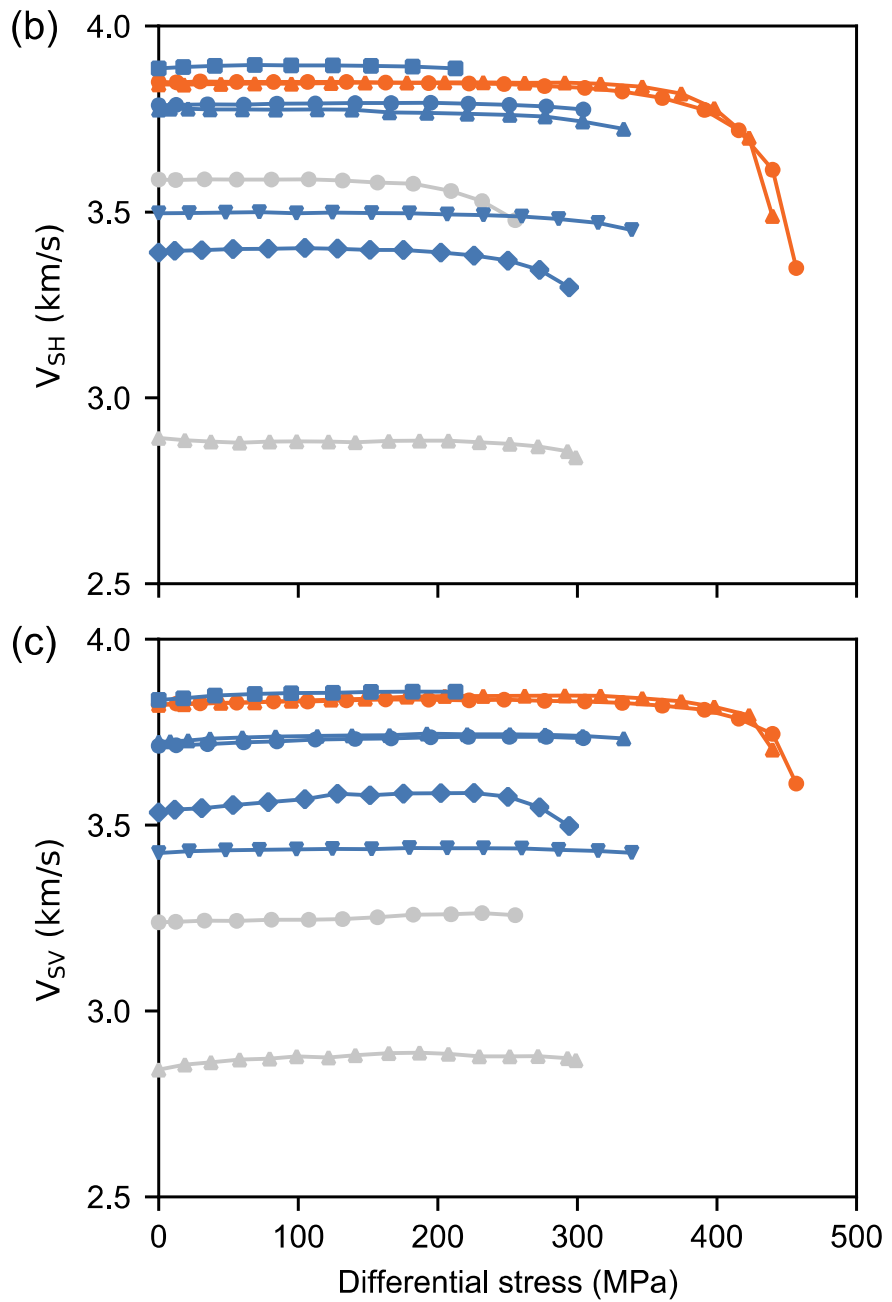

Figure 5. Elastic wave velocities recorded during deformation experiments. P- (a), SH- (b), and SV-(c) wave velocities are plotted as a function of differential stress. 


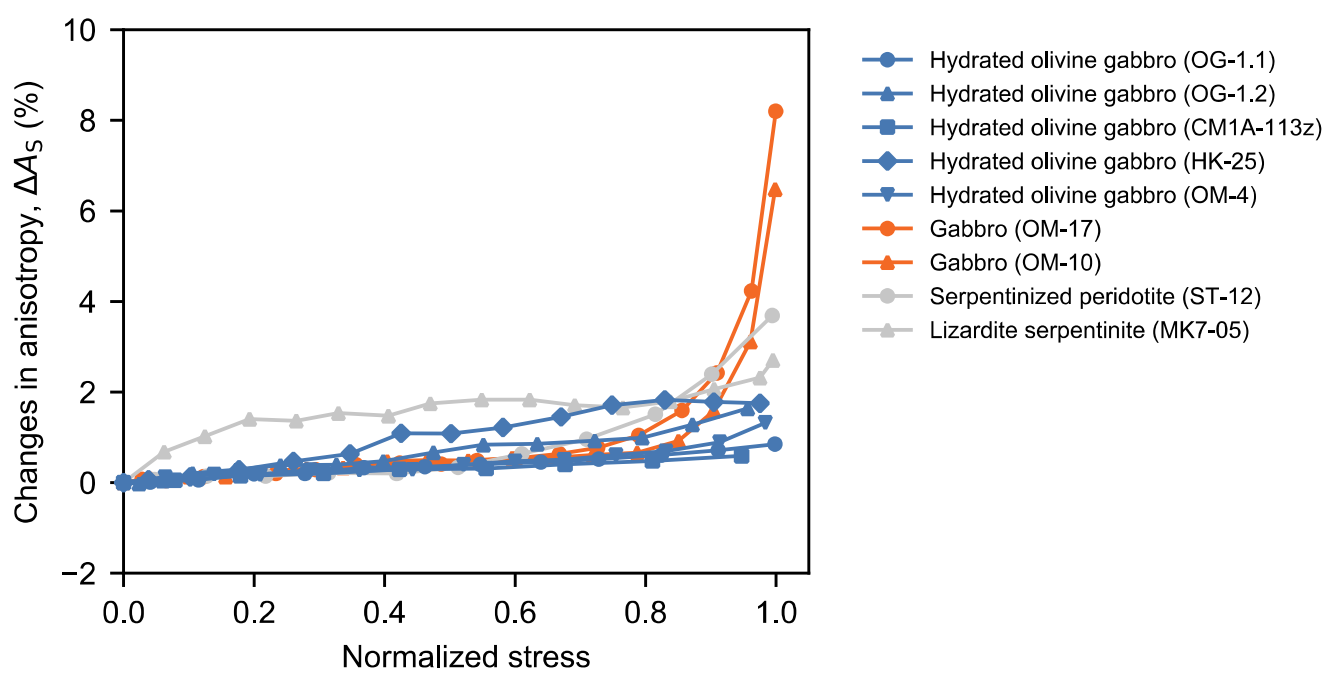

Figure 6. Relative changes in S-wave anisotropy during deformation experiments. Differential stress is normalized by the maximum differential stress in each sample. S-wave anisotropy was calculated as $A_{\mathrm{S}}=\left(V_{\mathrm{SV}}-V_{\mathrm{SH}}\right) / \bar{V}_{\mathrm{S}} \times 100$, where $\bar{V}_{S}=\left(V_{\mathrm{SV}}+V_{\mathrm{SH}}\right) / 2$ [33].

In hydrated olivine gabbro samples, the elastic wave velocities remained almost constant during deformation but decreased by only $<3 \%$ prior to the maximum stress (Figure 5). S-wave anisotropy slightly increased during deformation of the olivine gabbros, likely due to the closure of pre-existing cracks oriented perpendicular to $\sigma_{1}$. However, the changes in S-wave anisotropy were much less dramatic than those observed as the gabbro samples approached the maximum stress (Figure 6). Similar trends were observed for the serpentinite and serpentinized peridotite samples. Note that the slightly larger changes in anisotropy (2-4\%) of the serpentinized ultramafic rocks than those of hydrated olivine gabbros $(<2 \%)$ were possibly caused by relatively higher initial porosities of the ultramafic samples. Deformation in such serpentinized ultramafic rocks is not dilatant, as it is reportedly accommodated by shear cracking preferentially along the basal planes of serpentine, rather than through the opening of axial cracks $[2,6]$. The behavior of elastic wave velocities during deformation of hydrated olivine gabbros is similar to that of highly serpentinized peridotites, but markedly different from that of gabbros. This indicates that the brittle deformation of hydrated olivine gabbro is not related to typical crack development during deformation as well as hydrated peridotite.

\subsection{Microstructure}

Post-deformation, samples were recovered, impregnated with epoxy, and cut perpendicular to the fault zone to prepare polished thin sections for observation with a $15 \mathrm{kV}$ scanning electron microscope (SEM). Figure 7 shows SEM images of representative microscale segments of the fault profile developed in each rock type. In these micrographs, the direction of axial compression is vertical. At sample scale, the faults develop at the angle of $20-30^{\circ}$ from the loading axis in all samples. The gabbro samples show swarms of cracks oriented subparallel to the compression axis on both sides of the faults (Figure 7a). This stress-induced axial cracking is consistent with the anisotropic changes in elastic wave velocities observed in these samples during deformation (Figure 5) and with results from previously tested dilatant rocks. In hydrated olivine gabbro samples, crack damage is limited to the immediate vicinity of the fault zone. Areas away from the fault zone remain essentially undeformed and are indistinguishable from the pre-deformation material (Figure $7 \mathrm{~b}$ ). Macroscopic failure in the olivine gabbros appears to result from the sudden occurrence of one or more major fractures, as opposed to the propagation and coalescence of axial cracks that are commonly observed in most crystalline rocks [5]. SEM images of the serpentinized peridotite and serpentinite samples (Figure 7c,d) show similar features to those of the hydrated olivine gabbros. These observations are consistent with the absence 
of marked velocity changes recorded during deformation of the hydrated olivine gabbros and ultramafic rocks (Figures 5 and 6).
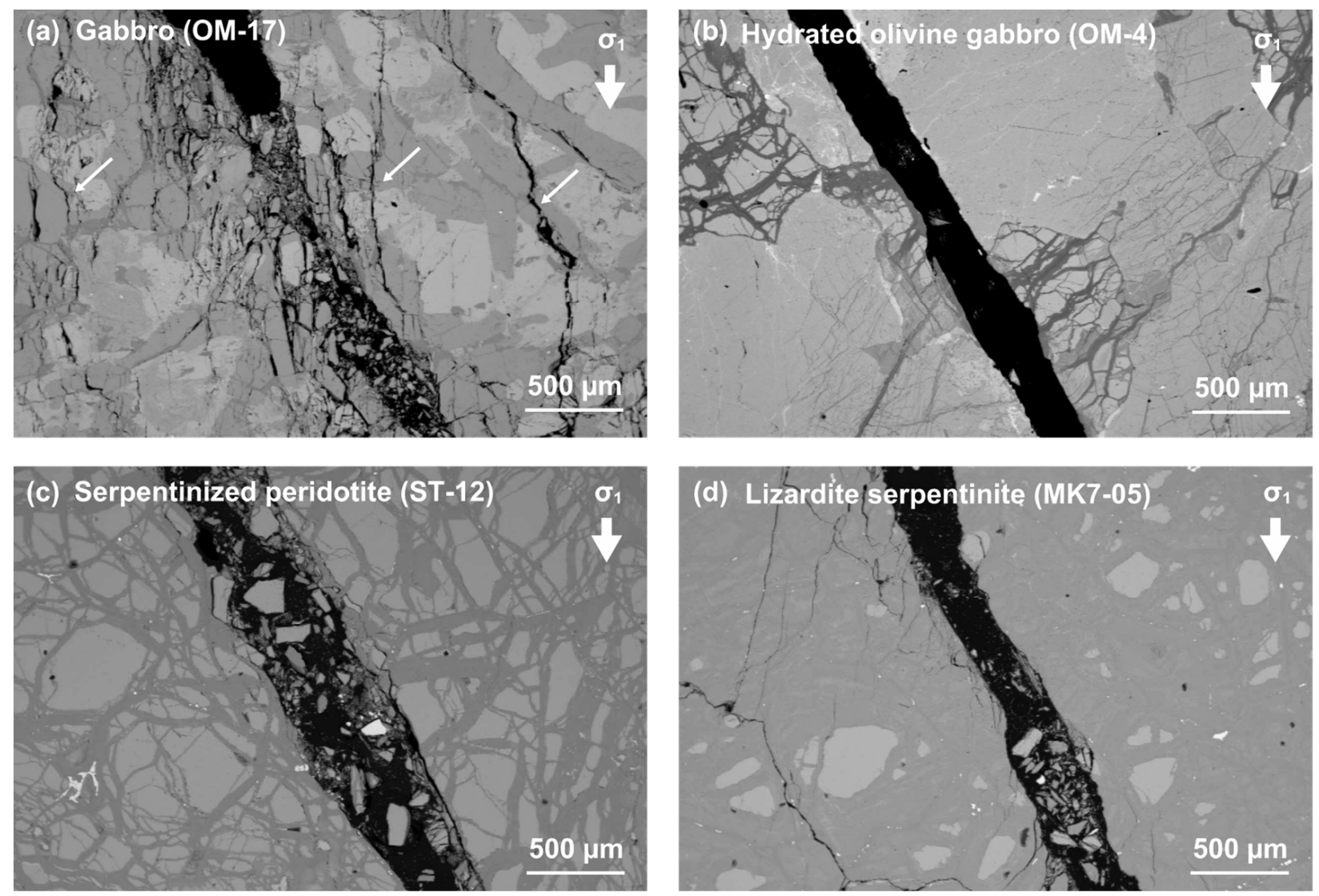

Figure 7. SEM images of fault planes in the failed samples recovered after deformation experiments: (a) gabbro, (b) hydrated olivine gabbro, (c) serpentinized peridotite, and (d) lizardite serpentinite. The loading axis $\sigma_{1}$ is in the vertical direction. White arrows in (a) indicate stress-induced cracks.

\section{Discussion}

\subsection{Non-Dilatant Brittle Deformation of Hydrated Olivine Gabbro}

We observed no remarkable changes in elastic wave velocities during the brittle deformation of olivine gabbros with 6-27\% hydrous minerals. In contrast, deformation in gabbro samples was characterized by a systematic decrease in wave velocities (Figures 5 and 6). In general, most crystalline rocks tend to exhibit significant volumetric dilation (dilatancy) during brittle deformation [35]. A number of experimental studies have documented dilatancy to be caused by the opening of microcracks aligned subparallel to $\sigma_{1}$, prior to the formation of a macroscopic fault (see [5] for a review). Since rock elasticity is closely related to the microstructure of cracks and pores, dilatant deformation results in a significant and anisotropic decrease in elastic wave velocities [25-30]. The absence of such changes in elastic wave velocities during brittle deformation of hydrated olivine gabbros indicates that deformation in these rocks is not associated with typical dilatancy.

To quantify the amount of dilatancy, we inverted the measured elastic wave velocity to obtain the axial crack density, using the effective medium theory. When $\left(x_{1}, x_{2}, x_{3}\right)$ represents orthogonal directions and $x_{3}$ is aligned with the loading axis, for a transversely isotropic medium, the elastic stiffness tensor component (i.e., P-wave modulus) in direction $x_{1}$, termed $C_{11}$, is related to $\mathrm{P}$-wave velocity along the direction normal to the loading axis $V_{\mathrm{P}}$ as:

$$
C_{11}=\rho V_{\mathrm{P}}^{2},
$$


where $\rho$ is the density [27]. Assuming a medium containing randomly oriented pennyshaped cracks, parallel to the $x_{1} x_{2}$ plane, and with no interaction between individual cracks, the normalized elastic stiffness $C_{11} / C_{11}^{0}$ is given by [4]:

$$
\frac{C_{11}}{C_{11}^{0}}=1-\frac{32\left(1-2 v_{0}+2 v_{0}^{2}\right)}{3\left(2-v_{0}\right)\left(1-2 v_{0}\right)} \gamma_{11},
$$

where $\gamma_{11}$ is the crack density oriented parallel to the loading axis (i.e., the axial crack density), and $C_{11}^{0}$ and $v_{0}$ are the reference P-wave modulus and Poisson's ratio of the crack-free matrix, respectively. Poisson's ratio $v$ is related to the elastic wave velocities by

$$
v=\frac{V_{\mathrm{P}}^{2}-2 \bar{V}_{\mathrm{S}}^{2}}{2\left(V_{\mathrm{P}}^{2}-\bar{V}_{\mathrm{S}}^{2}\right)} .
$$

For the reference parameters, we used initial values obtained before applying any differential stress; thus, our calculated crack densities represent relative changes during deformation. Since the direction $x_{2}$ is equivalent to $x_{1}$ for a transversely isotropic medium, the total crack density of axial cracks is given by: $\gamma=\gamma_{11}+\gamma_{22}=2 \gamma_{11}$. When cracks are assumed to be penny-shaped, the crack porosity added during deformation $\Delta \phi_{\mathrm{c}}$ can be expressed by:

$$
\Delta \phi_{\mathrm{c}}=2 \pi \Delta \gamma \alpha,
$$

Where $\alpha$ is the crack aspect ratio. The amount of dilatancy is often considered equivalent to the crack porosity [5]; thus, here we quantify the amount of dilatancy $\Delta \varepsilon_{\mathrm{v}}$ as $\Delta \phi_{\mathrm{c}}$. Figure 8 shows the total axial crack density added during deformation and the corresponding amount of dilatancy, assuming $\alpha=0.01$, which is a typical value for stress-induced axial cracks [25]. The amount of dilatancy calculated for gabbro samples $\left(\Delta \varepsilon_{\mathrm{V}}=0.4-0.6 \%\right.$, $\Delta \gamma=0.06-0.09)$ is consistent with that observed in previously tested crystalline rocks $[2,36]$. Hydrated olivine gabbros show almost no dilatancy $\left(\Delta \varepsilon_{\mathrm{V}}<0.1 \%, \Delta \gamma<0.01\right)$, similar to the serpentinized ultramafic rocks, which are known to be non-dilatant during brittle deformation [2,6]. These results suggest that brittle deformation in hydrated olivine gabbro would be non-dilatant and instead characterized by the sudden occurrence of a main fault, without the development of pervasive axial cracks throughout the deformed sample (Figure 7).

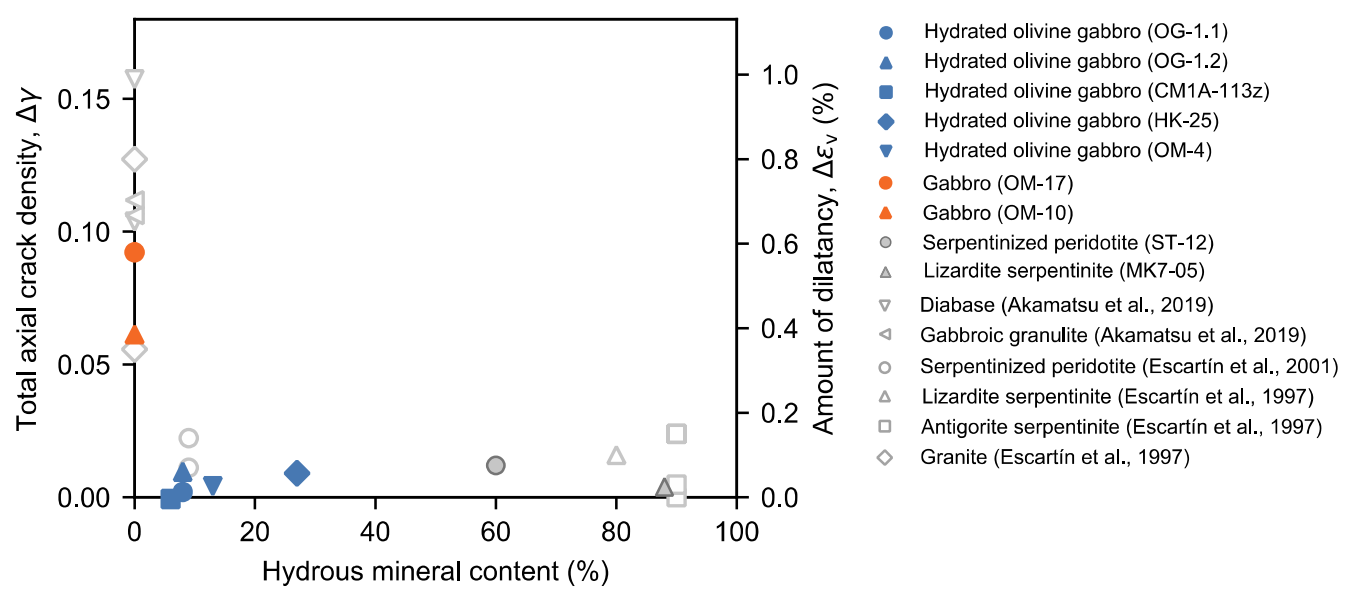

Figure 8. Relationship between the total axial crack density, amount of dilatancy, and hydrous mineral content for each experimental sample. The total axial crack density was calculated using the effective medium theory [4,27]. The amount of dilatancy was calculated as $\Delta \varepsilon_{\mathrm{V}}=\Delta \phi_{\mathrm{c}}=2 \pi \Delta \gamma \alpha$, using an aspect ratio of 0.01 . Moreover, plotted are experimental data for a range of dilatant and non-dilatant rocks reported by previous studies [2,6,36]. Experimental conditions were $20 \mathrm{MPa}$ and room temperature for data from Akamatsu et al. [36] and 50-200 MPa and room temperature for data from Escartín et al. [2,6]. 
Previous experimental studies have reported the non-dilatant brittle deformation of serpentine-bearing rocks. Escartín et al. [2] found that highly foliated serpentinites do not exhibit dilatancy during brittle deformation, because the deformation is accommodated purely by shear cracks along the weak basal planes of serpentine, resulting in a negligible volume increase. Due to the absence of dilatancy, meanwhile, elastic wave velocities in antigorite have been observed to stay nearly unchanged during deformation, even immediately prior to brittle failure [4]. A similar brittle behavior was observed in peridotite with only $10 \%$ lizardite and chrysotile. The deformation of these rocks was accommodated primarily by shear cracking in serpentine at stress below those required for the nucleation of intragranular cracks within olivine, resulting in a non-dilatant mode of brittle deformation [6]. These observations are consistent with the absence of remarkable changes in elastic wave velocities observed during the deformation of lizardite serpentinite (MK7-05) and 51\% serpentinized peridotite (ST-12) in this study. The predominance of shear cracking in serpentine-bearing rocks has been supported quantitatively by measurements of fracture toughness $K_{\mathrm{Ic}}$, which, characterizes the stress required for the opening of axial "mode I" cracks and has been shown to have a much higher value in antigorite than in granite [37]. This suggests that shear sliding can be the favored mode of crack development in serpentine-bearing rocks. Furthermore, recent experimental achievements on phyllosilicate-rich rocks indicate that the lack of significant dilatancy can be resulted from strain localization upon the collapse of intracrystalline nano-scale porosity of phyllosilicates (e.g., [38]). Based on interpretations from these previous studies, the absence of dilatancy during the deformation of our hydrated olivine gabbros can be explained if failure occurs from shear cracking in the phyllosilicates such as serpentine, rather than from tensile crack opening within the load-bearing minerals.

\subsection{Strength Reduction and Deformation Mechanism of Hydrated Olivine Gabbro}

In addition to the absence of stress-induced changes in elastic wave velocities during deformation, we observed the nonlinear relationship between the brittle strength and the hydrous mineral content of gabbroic rocks, where olivine gabbros with hydrous mineral content $>6 \%$ showed much smaller brittle strength than that of gabbros (Figure 4 ). Such a strength reduction has been reported for partially serpentinized peridotite by Escartín et al. [6]. They observed that the strength of peridotites decreased dramatically to that of pure serpentinite when the serpentinization degree exceeded $\sim 10 \%$. They concluded that this weakening occurs because serpentine minerals interconnect along olivine grain boundaries and act as a weak phase, even at these low degrees of serpentinization. Such networks of weak phase can favor stress partitioning and local mechanical instabilities at the grain scale (e.g., [39]), which has been confirmed by high-pressure experiments on serpentinized peridotite [24]. Meanwhile, Okazaki and Hirth [40] conducted highpressure triaxial deformation experiments on chlorite-bearing mafic schists and suggested that small amounts of chlorite could weaken the sample strength, in a similar manner to that suggested for serpentinized peridotite. Our calculations of crack density, combined with microstructural observations of the failed samples, demonstrate that the formation of macroscopic fault in hydrated olivine gabbro does not involve the development of significant axial "mode I" cracks (Figure 7). These hydrated olivine gabbro samples were characterized by olivine grains replaced by serpentine and intragranular cracks filled with chlorite in plagioclase. These observations indicate that substantially weak hydrous phases such as serpentine and chlorite can act as a weak phase that causes strain/stress localization in a similar mechanism to that of serpentinized peridotite $[6,24]$. Note that CM1A-113z showed much lower strength than those of the other hydrated olivine gabbros even at low hydrous mineral content (Figure 3). This implies that the strength of gabbroic rock may be dependent not only on the amount of hydrous minerals but also on the distribution of hydrous minerals in the sample such as heterogeneity or interconnectivity [41].

Based on the experimental results, we suggest that the brittle failure of hydrated olivine gabbro and gabbro occurs by different mechanisms, as illustrated in Figure 9. Ac- 
cording to previous studies, dilatant brittle failure is often interpreted in several stages [42]. In the initial stage of deformation, pre-existing cracks oriented at high angles to the loading direction are closed (stage I). This closure is associated with a slight increase in volumetric strain and elastic wave velocities, although these effects were not clearly observed in our samples, probably due to the low initial rock porosities. Following stage I, the rock behaves as an elastic medium and the volumetric strain increases linearly with stress (stage II). At $30-60 \%$ of the failure stress, cracks oriented subparallel to the loading direction begin to develop. This leads to a deviation from linearity in the stress-volumetric strain curve and a gradual decrease in elastic wave velocities (stage III). Finally, these cracks propagate and coalesce to form a macroscopic fracture zone, resulting in significant volume dilation and velocity reduction (stage IV). In contrast, the hydrated olivine gabbros appeared to deform by a different process, which we outline as follows: The initial stages of olivine gabbro deformation follow the previous framework: pre-existing cracks close (stage I) and the rock deforms elastically (stage II). However, the deformation is then accommodated primarily by shear cracking in substantially weak minerals such as serpentine and chlorite, instead of by axial crack opening within the matrix minerals (Figure 7). As shear cracks do not generate any void space, the stress-volumetric strain curve remains linear and the elastic wave velocities are not affected. This makes the differential stress at the onset of shear cracking difficult to detect. Therefore, we interpreted the development of shear cracks as stage III', which is indistinguishable to stage II. As the differential stress increases further, the unstable propagation of shear cracks suddenly occurs to form a localized fault zone, identifiable by minor amounts of volume dilation and velocity reduction (stage IV). It is important to note that stage IV occurs at lower differential stress than is required for the failure of gabbro.

(a)

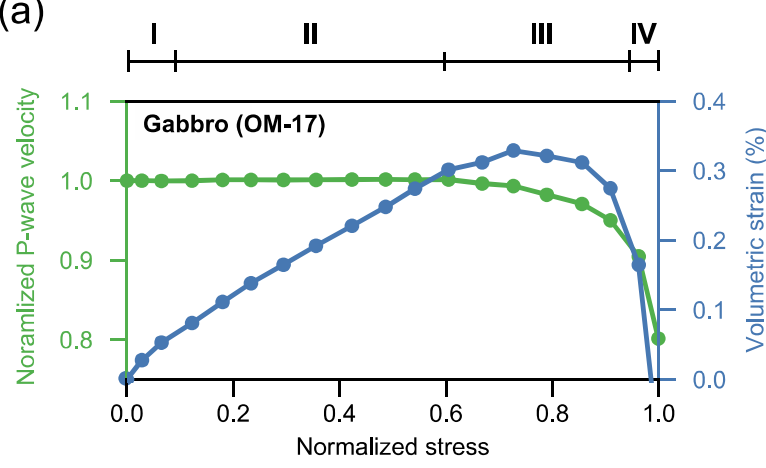

(c)

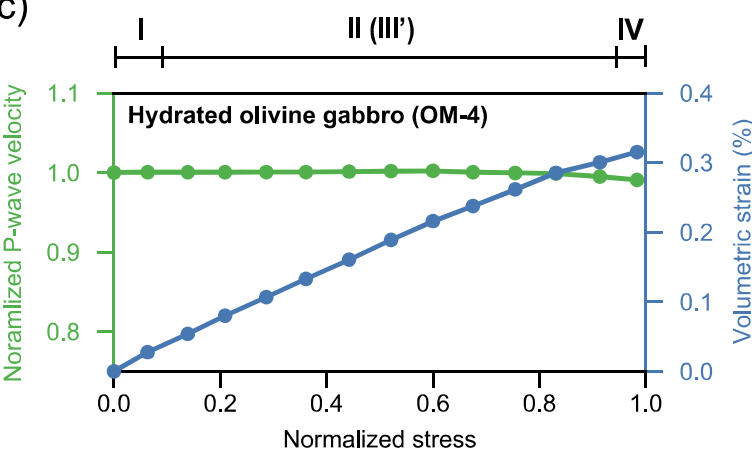

(b)

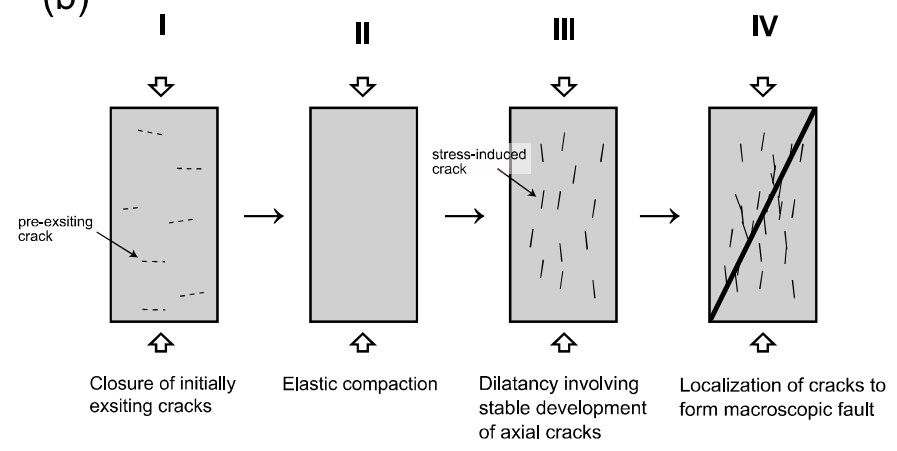

(d)

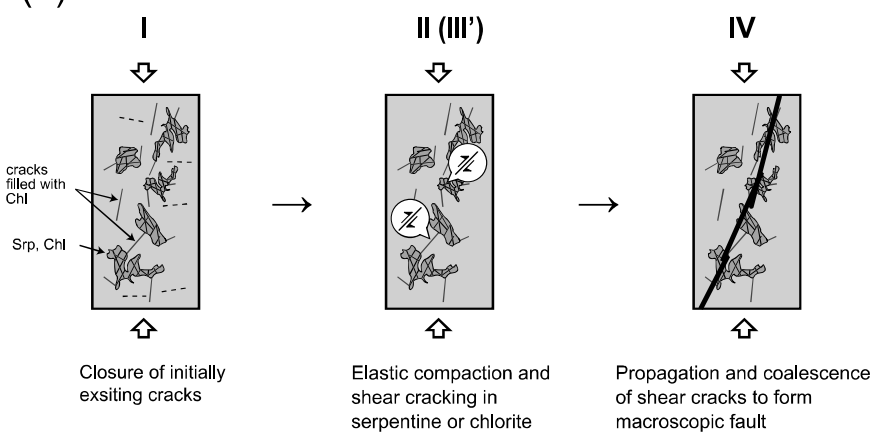

Figure 9. Ultrasonic and mechanical data with schematic diagrams showing the stages of brittle deformation for gabbro (OM-17) and hydrated olivine gabbro samples (OM-4). Normalized P-wave velocity and volumetric strain estimated from calculated crack density, assuming the aspect ratio to be 0.01 , are plotted against normalized differential stress (a,c). Schematic models of the brittle deformation mechanisms in gabbro and hydrated olivine gabbro (b,d). The onset of each stage of deformation in relation to the ultrasonic and mechanical data is shown at the top of $(\mathbf{a}, \mathbf{c})$, respectively. 
This study has focused on exploring the fundamental influence of hydration on the brittle deformation of gabbroic crustal rocks but did not explore the pressure dependence of strength and dilatancy in hydrated olivine gabbro. Previous studies have shown the strength of serpentinites and serpentinized peridotites to increase with confining pressure until the onset of ductile deformation (at a confining pressure of 150-350 MPa), while the amount of dilatancy remains negligible $[2,6]$. Some high-pressure deformation experiments have also shown that the presence of serpentine can govern the rheology of rocks even under the pressure of several giga-pascals [24,43]). Hydrated olivine gabbro may be expected to show similar brittle and plastic behaviors to that of serpentinite and serpentinized peridotite at higher pressure.

\subsection{Geophysical Implications}

Our experimental results suggest that the brittle and physical properties of the oceanic crust, which is mainly comprised of olivine-bearing gabbroic rocks, can be significantly changed as a result of hydration. In most geodynamics models, the oceanic crust has been considered to be much stronger than that of serpentinized mantle based on the strength of dry gabbroic rocks (e.g., [44]). However, the brittle strength of the oceanic crust can be reduced when the hydrous minerals such as serpentine and chlorite are present, even in small amount. This strength reduction could result in easy formation of fault in the oceanic crust where hydration occurs. Brittle faulting of the natural environment is often assumed to involve pervasive crack formation around fault zones, consistent with the dilatant behavior usually observed during the deformation of crystalline rocks (e.g., [45]). However, the absence of dilatancy during deformation of hydrated olivine gabbro would indicate that brittle deformation in the hydrated oceanic crust may result in a crack network entirely localized to the fault plane, as observed in our microstructural images of deformed samples (Figure $7 \mathrm{~b}$ ). The limited porosity generation associated with this would prevent fluid flow in directions perpendicular to the fault planes.

In the mantle, water trapped within fault zones reacts readily with wall-rock peridotite by serpentinization. The formation of serpentine causes a volumetric expansion that enhances cracking $[46,47]$. Serpentinization is geologically rapid at temperatures greater than $100{ }^{\circ} \mathrm{C}$ [48], meaning that the supply of water to faults is the key control on the lateral extent of hydration in the uppermost mantle [48,49]. In the oceanic crust, olivine is not the matrix mineral, meaning that less water is used in hydration reaction and less reaction-induced cracking occurs. The lateral fluid flow along cracks can be limited compared to the case in the uppermost mantle, and hydration could be confined to the vicinity of the fault zones. The extent of hydration in the mantle is commonly inferred from seismic wave velocities, because the seismic wave velocity of peridotite decreases with serpentinization [50]. Seismic wave velocity is also dependent on the presence of cracks. Therefore, the effects of both hydration and porosity should be accounted for when interpreting the seismic structure of the oceanic mantle [51]. In contrast, seismic wave velocities in gabbroic rocks are not highly sensitive to alteration, meaning that porosity is usually the primary influence on seismic wave velocity in the oceanic crust [52]. Our experimental data indicate that even slight hydration of the oceanic crust could inhibit the formation of pervasive crack networks during deformation, resulting in only minor changes in seismic wave velocities.

Gabbroic rocks containing hydrated olivine grains have been sampled by seafloor drilling, dredging, and submersibles at tectonic windows, such as oceanic core complexes near slow-spreading ridges (e.g., [7-10]), transform faults near fast-spreading ridges (e.g., $[11,12])$, and outcropping ophiolites (e.g., [13,14]). Since these fragments of the oceanic plate underwent hydration during and/or after the tectonic processes that caused their exposures, hydration of the oceanic crust might play a role in such tectonics. On the other hand, in the oceanic plate away from these settings, hydration occurs primarily by hydrothermal circulation through fractures caused by tectonic stress at the spreading ridges, which is often confined to the upper part of the oceanic crust. However, recent 
geophysical surveys have revealed that hydration occurs down to depths below the Moho due to water infiltration through bending-related faults, prior to subduction at outer-rise regions [15-23]. Assuming failure is non-dilatant due to hydration, we would expect only minor stress-induced crack damage around the bending-related faults. This could lead to a build-up of fluid pressure within the faults and a reduction in the effective confining pressure (i.e., lithostatic pressure) at a given depth, leading to rheological weakening of the faults in addition to the substantial weakening caused directly by hydration. Furthermore, the fault permeability would be increased, facilitating water penetration into the deeper parts of the oceanic plate. Note that the deeper parts of the oceanic crust must already be slightly hydrated to cause such weakening at the subduction zones. Thermal contraction may contribute to the primary hydration at the deeper parts of the oceanic crust. During cooling of the oceanic lithosphere, cracking can occur due to thermal stress even down to the depths of the uppermost mantle, which results in fluid infiltration and hydration along fractures (e.g., [52]). Serpentinization-induced cracking can also follow such primary hydration due to thermal stress, leading to the formation of networks of hydrous minerals [31].

Pressure and temperature at the depths of the lower oceanic crust are much higher than the conditions used in our experiments but should be low enough that brittle deformation is dominant [53]. Although care must be taken when applying low pressure and temperature experimental results to the oceanic crust, our results can provide new insights that aid the interpretation of geophysical data from the oceanic plates.

\section{Conclusions}

Triaxial deformation experiments were conducted on gabbroic rocks with various degrees of hydration, at room temperature and with a confining pressure of $20 \mathrm{MPa}$. Elastic wave velocities were measured during the deformation. While gabbros exhibited the typical dilatant behavior expected of crystalline rocks, hydrated olivine gabbros were characterized by weak brittle strength and the absence of dilatancy. These characteristics were consistent with microstructural observations in which hydrated olivine gabbros showed highly localized deformation structures with no trace of stress-induced axial crack opening. Our results suggest that the brittle deformation and strain localization of hydrated olivine gabbro occurs by the development of shear cracks in mechanically weak hydrous minerals such as serpentine and chlorite. Our study indicates that the brittle behavior of the oceanic crust can be drastically modified by hydration.

Author Contributions: Conceptualization, Y.A.; methodology, Y.A. and K.N.; formal analysis, Y.A.; investigation, Y.A. and K.N.; resources, I.K. and K.N.; writing-original draft preparation, Y.A.; writing-review and editing, Y.A., K.N. and I.K.; supervision, I.K.; funding acquisition, Y.A. and I.K. All authors have read and agreed to the published version of the manuscript.

Funding: This study was supported by JSPS KAKENHI Grant Numbers 20H00200 and 20J22228.

Data Availability Statement: Experimental data are available upon request to the corresponding author.

Acknowledgments: We thank E. Takazawa at Niigata University and K. Hatakeyama at Meisei University for providing the outcrop samples collected from the Samail ophiolite. We also thank N. Abe and K. Okazaki at JAMSTEC for providing the core sample by Oman Drilling Project. Comments from three anonymous reviewers greatly improved the manuscript. This study was supported by the Japan Society for the Promotion of Science (Grant Numbers: 20H00200 and 20J22228).

Conflicts of Interest: The authors declare no conflict of interest.

\section{References}

1. Moore, D.E.; Lockner, D.A. Crystallographic controls on the frictional behavior of dry and water-saturated sheet structure minerals. J. Geophys. Res. 2004, 109. [CrossRef]

2. Escartín, J.; Hirth, G.; Evans, B. Nondilatant brittle deformation of serpentinites: Implications for Mohr-Coulomb theory and the strength of faults. J. Geophys. Res. 1997, 102, 2897-2913. [CrossRef] 
3. Lefeldt, M.; Grevemeyer, I.; Goßler, J.; Bialas, J. Intraplate seismicity and related mantle hydration at the Nicaraguan trench outer rise. Geophys. J. Int. 2009, 178, 742-752. [CrossRef]

4. David, E.C.; Brantut, N.; Hansen, L.N.; Mitchell, T.M. Absence of stress-induced anisotropy during brittle deformation in antigorite serpentinite. J. Geophys. Res. Solid Earth 2018, 123, 616-644. [CrossRef]

5. Paterson, M.S.; Wong, T.-F. Experimental Rock Deformation-The Brittle Field; Springer Science \& Business Media: Berlin/Heidelberg, Germany, 2005; ISBN 9783540240235.

6. Escartín, J.; Hirth, G.; Evans, B. Strength of slightly serpentinized peridotites: Implications for the tectonics of oceanic lithosphere. Geology 2001, 29, 1023-1026. [CrossRef]

7. Beard, J.S.; Frost, B.R.; Fryer, P.; McCaig, A.; Searle, R.; Ildefonse, B.; Zinin, P.; Sharma, S.K. Onset and Progression of Serpentinization and Magnetite Formation in Olivine-rich Troctolite from IODP Hole U1309D. J. Petrol. 2009, 50, 387-403. [CrossRef]

8. Michibayashi, K.; Hirose, T.; Nozaka, T.; Harigane, Y.; Escartin, J.; Delius, H.; Linek, M.; Ohara, Y. Hydration due to high-T brittle failure within in situ oceanic crust, $30^{\circ} \mathrm{N}$ Mid-Atlantic Ridge. Earth Planet. Sci. Lett. 2008, 275, 348-354. [CrossRef]

9. Nozaka, T.; Fryer, P. Alteration of the Oceanic Lower Crust at a Slow-spreading Axis: Insight from Vein-related Zoned Halos in Olivine Gabbro from Atlantis Massif, Mid-Atlantic Ridge. J. Petrol. 2011, 52, 643-664. [CrossRef]

10. Suhr, G.; Hellebrand, E.; Johnson, K.; Brunelli, D. Stacked gabbro units and intervening mantle: A detailed look at a section of IODP Leg 305, Hole U1309D. Geochem. Geophys. Geosyst. 2008, 9. [CrossRef]

11. Manning, C.E.; Weston, P.E.; Mahon, K.I. Rapid high-temperature metamorphism of East Pacific Rise gabbros from Hess Deep. Earth Planet. Sci. Lett. 1996, 144, 123-132. [CrossRef]

12. Nozaka, T.; Wintsch, R.P.; Meyer, R. Serpentinization of olivine in troctolites and olivine gabbros from the Hess Deep Rift. Lithos 2017, 282-283, 201-214. [CrossRef]

13. Kelemen, P.B.; Matter, J.M.; Teagle, D.A.H.; Coggon, J.A.; The Oman Drilling Project Science Team. Proceedings of the Oman Drilling Project.; International Ocean Discovery Program: La Jolla, CA, USA, 2020. [CrossRef]

14. Korenaga, J.; Kelemen, P.B. Origin of gabbro sills in the Moho transition zone of the Oman ophiolite: Implications for magma transport in the oceanic lower crust. J. Geophys. Res. 1997, 102, 27729-27749. [CrossRef]

15. Contreras-Reyes, E.; Grevemeyer, I.; Flueh, E.R.; Reichert, C. Upper lithospheric structure of the subduction zone offshore of southern Arauco peninsula, Chile, at $\sim 38^{\circ}$ S. J. Geophys. Res. 2008, 113. [CrossRef]

16. Fujie, G.; Kodaira, S.; Yamashita, M.; Sato, T.; Takahashi, T.; Takahashi, N. Systematic changes in the incoming plate structure at the Kuril trench. Geophys. Res. Lett. 2013, 40, 88-93. [CrossRef]

17. Grevemeyer, I.; Ranero, C.R.; Flueh, E.R.; Kläschen, D.; Bialas, J. Passive and active seismological study of bending-related faulting and mantle serpentinization at the Middle America trench. Earth Planet. Sci. Lett. 2007, 258, 528-542. [CrossRef]

18. Ranero, C.R.; Morgan, J.P.; McIntosh, K.; Reichert, C. Bending-related faulting and mantle serpentinization at the Middle America trench. Nature 2003, 425, 367-373. [CrossRef]

19. Shillington, D.J.; Bécel, A.; Nedimović, M.R.; Kuehn, H.; Webb, S.C.; Abers, G.A.; Keranen, K.M.; Li, J.; Delescluse, M.; MatteiSalicrup, G.A. Link between plate fabric, hydration and subduction zone seismicity in Alaska. Nat. Geosci. 2015, 8, 961-964. [CrossRef]

20. Wan, K.; Xia, S.; Cao, J.; Sun, J.; Xu, H. Deep seismic structure of the northeastern South China Sea: Origin of a high-velocity layer in the lower crust: The Nature of HVL in Northeastern SCS. J. Geophys. Res. Solid Earth 2017, 122, 2831-2858. [CrossRef]

21. Cai, C.; Wiens, D.A.; Shen, W.; Eimer, M. Water input into the Mariana subduction zone estimated from ocean-bottom seismic data. Nature 2018, 563, 389-392. [CrossRef]

22. Key, K.; Constable, S.; Matsuno, T.; Evans, R.L.; Myer, D. Electromagnetic detection of plate hydration due to bending faults at the Middle America Trench. Earth Planet. Sci. Lett. 2012, 351-352, 45-53. [CrossRef]

23. Naif, S.; Key, K.; Constable, S.; Evans, R.L. Water-rich bending faults at the Middle America Trench. Geochem. Geophys. Geosyst. 2015, 16, 2582-2597. [CrossRef]

24. Ferrand, T.P.; Hilairet, N.; Incel, S.; Deldicque, D.; Labrousse, L.; Gasc, J.; Renner, J.; Wang, Y.; Green, H.W.; Schubnel, A. Dehydration-driven stress transfer triggers intermediate-depth earthquakes. Nat. Commun. 2017, 8, 15247. [CrossRef] [PubMed]

25. Fortin, J.; Stanchits, S.; Vinciguerra, S.; Guéguen, Y. Influence of thermal and mechanical cracks on permeability and elastic wave velocities in a basalt from Mt. Etna volcano subjected to elevated pressure. Tectonophysics 2011, 503, 60-74. [CrossRef]

26. Nicolas, A.; Fortin, J.; Regnet, J.B.; Dimanov, A.; Guéguen, Y. Brittle and semi-brittle behaviours of a carbonate rock: Influence of water and temperature. Geophys. J. Int. 2016, 206, 438-456. [CrossRef]

27. Sayers, C.M.; Kachanov, M. Microcrack-induced elastic wave anisotropy of brittle rocks. J. Geophys. Res. 1995, 100, 4149-4156. [CrossRef]

28. Schubnel, A.; Benson, P.M.; Thompson, B.D.; Hazzard, J.F.; Young, R.P. Quantifying Damage, Saturation and Anisotropy in Cracked Rocks by Inverting Elastic Wave Velocities. In Rock Damage and Fluid Transport, Part I; Dresen, G., Zang, A., Stephansson, O., Eds.; Birkhäuser Basel: Basel, Switzerland, 2006; pp. 947-973. ISBN 9783764377120.

29. Zaima, K.; Katayama, I. Evolution of elastic wave velocities and amplitudes during triaxial deformation of Aji granite under dry and water-saturated conditions. J. Geophys. Res. Solid Earth 2018, 123, 9601-9614. [CrossRef]

30. Akamatsu, Y.; Katayama, I.; Tonegawa, T. Changes in elastic wave velocity during brittle deformation of gabbro and peridotite: Implications for oceanic Moho reflectivity. Earth Planet. Sci. Lett. 2021, 568, 117036. [CrossRef] 
31. Yoshida, K.; Okamoto, A.; Shimizu, H.; Oyanagi, R.; Tsuchiya, N. Oman Drilling Project Phase 2 Science Party Fluid infiltration through oceanic lower crust in response to reaction-induced fracturing: Insights from serpentinized troctolite and numerical models. J. Geophys. Res. Solid Earth 2020, 125. [CrossRef]

32. Nicolas, A.; Mainprice, D.; Boudier, F. High-temperature seawater circulation throughout crust of oceanic ridges: A model derived from the Oman ophiolites. J. Geophys. Res. 2003, 108. [CrossRef]

33. Wang, Q.; Bagdassarov, N.; Ji, S. The Moho as a transition zone: A revisit from seismic and electrical properties of minerals and rocks. Tectonophysics 2013, 609, 395-422. [CrossRef]

34. Lockner, D.A.; Walsh, J.B.; Byerlee, J.D. Changes in seismic velocity and attenuation during deformation of granite. J. Geophys. Res. 1977, 82, 5374-5378. [CrossRef]

35. Brace, W.F.; Paulding, B.W., Jr.; Scholz, C. Dilatancy in the fracture of crystalline rocks. J. Geophys. Res. 1966, 71, $3939-3953$. [CrossRef]

36. Akamatsu, Y.; Hatakeyama, K.; Katayama, I. Contrasting dilatant behaviors of mafic and ultramafic rocks based on triaxial deformation experiments. J. Mineral. Petrol. Sci. 2019, 114, 79-86. [CrossRef]

37. David, E.C.; Brantut, N.; Hirth, G. Sliding crack model for nonlinearity and hysteresis in the triaxial stress-strain curve of rock, and application to antigorite deformation. J. Geophys. Res. Solid Earth 2020, 125. [CrossRef]

38. Bonnelye, A.; Schubnel, A.; David, C.; Henry, P.; Guglielmi, Y.; Gout, C.; Fauchille, A.; Dick, P. Strength anisotropy of shales deformed under uppermost crustal conditions. J. Geophys. Res. Solid Earth 2017, 122, 110-129. [CrossRef]

39. Burnley, P.C. The importance of stress percolation patterns in rocks and other polycrystalline materials. Nat. Commun. 2013, 4, 2117. [CrossRef]

40. Okazaki, K.; Hirth, G. Deformation of mafic schists from subducted oceanic crust at high pressure and temperature conditions. Tectonophysics 2020, 774, 228217. [CrossRef]

41. Ferrand, T.P. Seismicity and mineral destabilizations in the subducting mantle up to 6 GPa, $200 \mathrm{~km}$ depth. Lithos 2019, 334-335, 205-230. [CrossRef]

42. Scholz, C.H. The Mechanics of Earthquakes and Faulting; Cambridge University Press: Cambridge, UK, 2002.

43. Gasc, J.; Hilairet, N.; Yu, T.; Ferrand, T.; Schubnel, A.; Wang, Y. Faulting of natural serpentinite: Implications for intermediatedepth seismicity. Earth Planet. Sci. Lett. 2017, 474, 138-147. [CrossRef]

44. Escartín, J.; Hirth, G.; Evans, B. Effects of serpentinization on the lithospheric strength and the style of normal faulting at slow-spreading ridges. Earth Planet. Sci. Lett. 1997, 151, 181-189. [CrossRef]

45. Scholz, C.H.; Sykes, L.R.; Aggarwal, Y.P. Earthquake prediction: A physical basis. Science 1973, 181, 803-810. [CrossRef]

46. Jamtveit, B.; Malthesorenssen, A.; Kostenko, O. Reaction enhanced permeability during retrogressive metamorphism. Earth Planet. Sci. Lett. 2008, 267, 620-627. [CrossRef]

47. Kelemen, P.B.; Hirth, G. Reaction-driven cracking during retrograde metamorphism: Olivine hydration and carbonation. Earth Planet. Sci. Lett. 2012, 345-348, 81-89. [CrossRef]

48. Macdonald, A.H.; Fyfe, W.S. Rate of serpentinization in seafloor environments. Tectonophysics 1985, 116, 123-135. [CrossRef]

49. Hatakeyama, K.; Katayama, I.; Hirauchi, K.-I.; Michibayashi, K. Mantle hydration along outer-rise faults inferred from serpentinite permeability. Sci. Rep. 2017, 7. [CrossRef]

50. Christensen, N.I. Serpentinites, Peridotites, and Seismology. Int. Geol. Rev. 2004, 46, 795-816. [CrossRef]

51. Hatakeyama, K.; Katayama, I. Pore fluid effects on elastic wave velocities of serpentinite and implications for estimates of serpentinization in oceanic lithosphere. Tectonophysics 2020, 775, 228309. [CrossRef]

52. Korenaga, J. Thermal cracking and the deep hydration of oceanic lithosphere: A key to the generation of plate tectonics? J. Geophys. Res. 2007, 112. [CrossRef]

53. McKenzie, D.; Jackson, J.; Priestley, K. Thermal structure of oceanic and continental lithosphere. Earth Planet. Sci. Lett. 2005, 233, 337-349. [CrossRef] 